Research Article

\title{
Analysis of Deformation and Stress Characteristics of Anchored-Frame Structures for Slope Stabilization
}

\author{
Wei-na Ye $\mathbb{D}$, Yong Zhou, and Shuai-hua Ye \\ School of Civil Engineering, Lanzhou University of Technology, Lanzhou, China \\ Correspondence should be addressed to Wei-na Ye; yeweina163@163.com
}

Received 29 June 2020; Revised 18 November 2020; Accepted 28 November 2020; Published 15 December 2020

Academic Editor: Qiang Tang

Copyright (C) 2020 Wei-na Ye et al. This is an open access article distributed under the Creative Commons Attribution License, which permits unrestricted use, distribution, and reproduction in any medium, provided the original work is properly cited.

\begin{abstract}
In recent years, anchored-frame structures are widely being used in road slopes for stabilization and improvement. The technology of frame structure with anchors is becoming more and more mature, but the pertinent theory lags behind the application. While more attention is being paid to the control of deformation, there is still no uniform solution to the calculation of deformation in the anchored-frame structures. According to the classical laterla earth pressure theory and static equilibrium, this paper improves the calculation method of lateral earth pressure and derives the calculation formula of slope-induced lateral earth pressure. At the same time, based on the elastic foundation beam model, the columns and beams are treated as a whole system, and the appropriate elastic frame beam model is established. The formula of the deformation and bending moments for the columns and beams in the anchored-frame structures are derived. Additionally, the calculated results based on the abovementioned newly derived formulas are compared with those of finite element simulations for a simulated case study. The results of simulation and analytical calculation are basically consistent, which prove the feasibility of the new analytical method.
\end{abstract}

\section{Introduction}

With the acceleration of road construction, road slopes are increasing drastically. In the last few decades, the frame structures with anchors have been widely used in slope engineering, particularly in road slopes, where the theoretical research lags behind the application [1-7]. In fact, the majority of attention has been paid to the strength and deformation behavior in slope stability analyses [8-12]. Though the strength-related stability of slopes has received widespread attentions in many engineered slopes, there is still no unified analysis method for the deformation of the frame structures with anchors [13-16]. Only limited work has been performed on the calculation method of the deformation of the frame structures with anchors. In those previous studies, as discussed by Zhou et al. [17], the deformation of prestressed anchors was in contrast with the deformation of slope. However, the deformation of the soil behind the retaining wall, which is part of the frame structure, was neglected, so it may cause certain errors. Some work (e.g., work of Liang et al. [18], Tang et al. [19], and Xiao et al. [20]) do not treat the frame structure with prestressed anchors as a unified system, while others (e.g., work of Han et al. [21], Fang et al. [22], Zhang et al. [23], and Bringkgreve and Vermeer [24]) simulated an actual engineering case using finite element modeling engineering [25, 26]. For example, He et al. [27] analyzed the interactions between the prestressed anchored foundation beam and foundation by means of the elastic foundation beam model [28] which was proposed by E. Winkler in 1876. Zenkour [29] investigated the state of stressed and displacement of elastic plates using simple and mixed shear deformation theories. Liew et al. [30] explored the differential quadrature method for Mindlin plates on Winkler foundations.

This paper describes an improved analytical method for earth pressure determination and derives formula of earth pressure suitable for the slope using the classical elasticity theory $[31,32]$. The improved method takes into account the surface load on the slope top and the angle of friction between the retaining wall and the soil [33-36]. Considering the compressive deformation of the soil, the beam and the column are treated as a whole system. Then, the elastic 
foundation beam model of the frame structure with anchors is established by using the elastic foundation beam model. The deformation and bending moment formula of the column and beam are derived at the least. In addition, the calculation is compared with the simulation results, which proves the correctness and reliability of the calculation method and provides a valuable reference for similar engineering design in the future.

\section{Deformation and Bending Moment in Frame Structures}

2.1. Deformation Calculation of the Frame Structures. The frame structure is composed a series of parallel beams and columns that are orthogonally intersected, and the intersection points are anchored into the slope. The deformation and bending moments of the frame structure with anchors is caused by the lateral earth pressure and the prestresses of the anchors. The deformation of the column and beam are as follows:

$$
\left\{\begin{array}{l}
\Delta_{x}=\Delta_{x p}+\delta_{x} \\
\Delta_{y}=\Delta_{y p}+\delta_{y}
\end{array}\right.
$$

where $\Delta_{x}$ and $\Delta_{y}$ are the deformation of column and beam, respectively; $\Delta_{x p}$ and $\Delta_{y p}$ are the deformation of column and beam under the lateral earth pressure, respectively; and $\delta_{x}$ and $\delta_{y}$ are the deformation of column under the prestress of anchors, respectively.

\subsection{Bending Moment Calculation of the Frame Structures.}

The bending moments of the column and beam are as follows:

$$
\left\{\begin{array}{l}
M_{x}=M_{x p}+m_{x} \\
M_{y}=M_{y p}+m_{y}
\end{array}\right.
$$

where $M_{x}$ and $M_{y}$ are the bending moment of the column and beam, respectively; $M_{x p}$ and $M_{y p}$ are the bending moment of column and beam under earth pressure, respectively; and $m_{x}$ and $m_{y}$ are the bending moment of column under the prestress of anchors, respectively.

\section{Deformation and Bending Moment Calculation under Lateral Earth Pressure}

3.1. Improved Lateral Earth Pressure Calculation Method. The magnitude and distribution on the wall of the additional lateral earth pressure are related to the magnitude and distribution of the additional surface or surcharge load on the top of the slope. The load should be considered in design and stability analysis. In this paper, the static equilibrium method is adopted. Because there are few studies of determination of the critical slope surface about the slope supported by anchored-frame structures, the potential slip surface is assumed as a straight line for getting the maximum of lateral earth pressure considering the friction between the soil and the wall and the surface load on the slope top, as shown in Figure 1.

If the force $P_{a}$ acts on the slope, then the force $P_{a}$ and soil weight, surface load on the slope top, and frictional resistance satisfy the static equilibrium:

$$
c l_{A C}+N \tan \varphi-P_{\mathrm{a}} \sin (\theta+\delta-\alpha)=F_{W} \sin \theta,
$$

in which

$$
\begin{aligned}
F_{W} & =q l_{B C}+G=\left(q+\frac{\gamma H}{2}\right) \frac{H \sin (\alpha-\theta)}{\sin \alpha \sin \theta}, \\
l_{A C} & =\frac{H}{\sin \theta}, \\
l_{B C} & =\frac{H \sin (\alpha-\theta)}{\sin \alpha \sin \theta}, \\
G & =\gamma \times \frac{1}{2} \times \frac{H}{\sin \theta} \times \frac{H}{\sin \alpha} \times \sin (\alpha-\theta)=\frac{\gamma H^{2} \sin (\alpha-\theta)}{2 \sin \alpha \sin \theta}, \\
N & =F_{W} \cos \theta+P_{\mathrm{a}} \sin (\theta+\delta-\alpha),
\end{aligned}
$$

where $c$ is the cohesion of the soil, $\varphi$ is the angle of internal friction of the soil, $H$ is the height of the slope, $\theta$ is the angle between the critical sliding surface and the horizontal plane, $\alpha$ is the angle between the anchor and the horizontal plane, $\gamma$ is the unit weight of the soil, $q$ is the surface load on the top of the slope, and $\delta$ is the angle of friction between the soil and retaining wall.

The determination of the slip surface or the position of point $\mathrm{C}$ depends on $\theta$. When $p_{a}$ reaches maximum, $\theta$ also reaches its maximum, so the position of point $C$ depends $\operatorname{on} \theta$. In order to reduce the difficulty of calculation, an indirect variable $x$ is introduced in this paper, that is, $I A D=x$. We can take the derivative of $x$, get the $x$ when the maximum of $p_{a}$, and then, get the maximum of $\theta$.

$$
\theta=\arctan \frac{1}{-a / b+\sqrt{a^{2} / b^{2}+(a+b \eta)+(a \tan \varphi+b) \cot \alpha / b(\tan \varphi+\eta)}}
$$




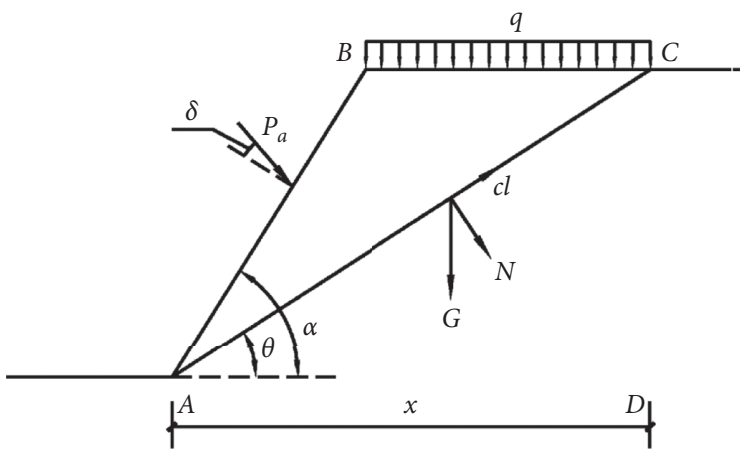

Figure 1: Earth pressure calculation.

where

The final calculation result of the lateral earth pressure is

$$
\left\{\begin{array}{c}
a=-\sin (\delta-\alpha) \tan \varphi-\cos (\delta-\alpha), \\
b=-\sin (\delta-\alpha)+\cos (\delta-\alpha) \tan \varphi, \\
\eta=2 c /(2 q+\gamma H) .
\end{array}\right.
$$

$$
P_{a}=\left(q H+\frac{\gamma H^{2}}{2}\right)\left[\frac{(\cot \theta-\cot \alpha) \sin (\theta-\varphi)}{\cos \varphi(a \sin \theta+b \cos \theta)}-\frac{\eta}{\sin \theta(a \sin \theta+b \cos \theta)}\right] .
$$

The earth pressure calculation of a homogeneous soil can be directly calculated according to formula (7). This paper mainly uses homogeneous soil slope as the research. Due to the complexity and variability of stratified soils, the slip surface is difficult to determine. In order to simplify the derivation, we also used a straight line to represent the critical slip surface. The soil weight, internal angle of friction, and cohesion of the stratified soils can be calculated by the weighted average method. Then, we use equation (5) to calculate the angle $\theta$ between the critical slip surface and the horizontal plane.

Then, we calculate angle $\theta$ between the critical slip surface and the horizontal plane and the weight $\mathrm{G}$. Then, we substitute $\theta$ and $G$ into equation (7) to obtain earth pressure.

3.2. Displacement Calculation under Earth Pressure. In the calculation of Earth pressure, the surface load on the slope top is taken as a part of the soil weight. However, there is no uniform form of Earth pressure distribution in the studies about the frame structure with anchors with considering the slope load. In this paper, according to the distribution form in the Technical Code for Building Slope Engineering (GB50330-2013) [37], the earth pressure distribution behind the frame structure with anchors is shown in Figure 2(a). The Earth pressure of the slope is as follows:

$$
e_{\mathrm{ah}}=\frac{E_{\mathrm{ah}}}{0.875 l_{x}} \text {. }
$$

When the earth pressure acts on the column, the column is a statically indeterminate structure subjected to a the distributed load. During the period of designing the frame structure with anchors, the force method is used to calculate the unknown force.

The column is considered as a cantilever beam. The bending moment subjects to the uniform load can be described by follows:

$$
M_{x q_{x}}= \begin{cases}-\frac{e_{\mathrm{hk}}}{3 l x} s_{x}\left(x+s_{0}\right)^{3}, & 0 \leq x \leq 0.25 l_{x}-s_{0}, \\ -\frac{e_{\mathrm{hk}}}{16} s_{x} l_{x}\left(x+s_{0}-\frac{l_{x}}{6}\right)-\frac{e_{\mathrm{hk}}}{4} s_{x}\left(x+s_{0}-\frac{l_{x}}{4}\right)^{2}, & 0.25 l_{x}-s_{0} \leq x \leq l_{x}-s_{0},\end{cases}
$$




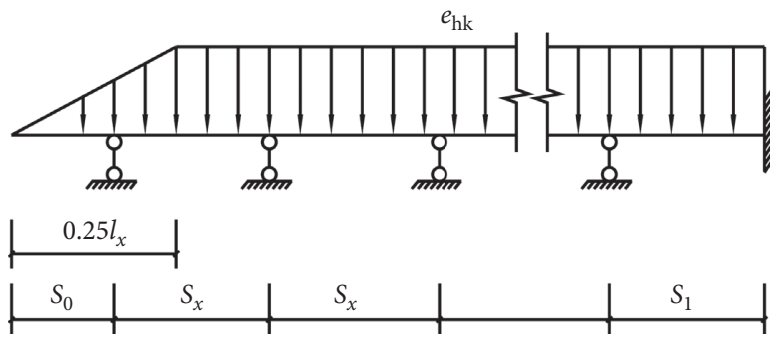

(a)

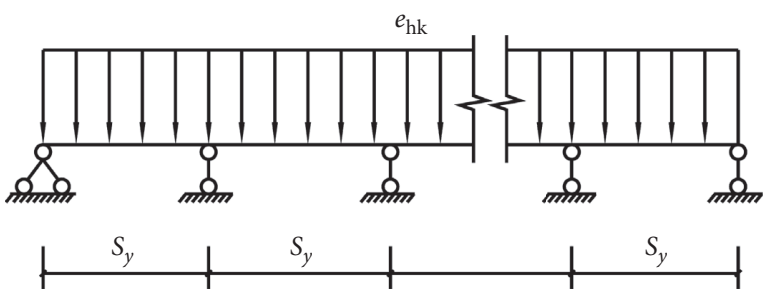

(b)

Figure 2: Calculation model. (a) Column. (b) Beam.

where $e_{\mathrm{hk}}$ is the standard value of the lateral earth pressure resultant force acting on the slope-supporting structure; $s_{x}$ is the vertical spacing among each anchor; $s_{0}$ is the distance between the first row anchors and the slope top; and $l_{x}$ is the slope height.

The bending moment of the column under a unit force is shown as follows:

$$
\begin{aligned}
\bar{M}_{x i} & = \begin{cases}0, & 0 \leq x \leq(i-1) s_{x}, \\
x-(i-1) s_{x}, & (i-1) s_{x} \leq x \leq l_{x}-s_{0},\end{cases} \\
\Delta_{i p} & =\int \frac{M_{x p} \bar{M}_{x i} \mathrm{~d} x}{E_{x} I_{x}},
\end{aligned}
$$

where $\bar{M}_{x i}$ is the bending moment of the column subject to the unit force and $\Delta_{i p}$ is the displacement of the column under the uniform load.

$$
\left\{\begin{array}{l}
\delta_{i i}=\sum \int \frac{\bar{M}_{x i} \bar{M}_{x i} \mathrm{~d} x}{E_{x} I_{x}}, \\
\delta_{i x}=\sum \int \frac{\bar{M}_{x i} \bar{M}_{x q_{x}} \mathrm{~d} x}{E_{x} I_{x}} .
\end{array}\right.
$$

In the meanwhile, the displacement is zero at the point of anchor:

$$
\Delta_{i p}+\delta F_{x i}=0,
$$

where $\delta_{i i}$ is the coefficient at the point $i^{\text {th }}$ when the unit force acts on the $i^{\text {th }}$ point, $\delta_{i x}$ is the coefficient at some point when the unit force acts on the $i^{\text {th }}$ point, $\delta$ is the matrix of coefficient, $F_{x i}$ is the concentrated force at the $i^{\text {th }}$ point, $E_{x}$ is the elastic modulus of the column, and $I_{x}$ is the inertia moment of the column.

Then, $F_{x i}$ is known, and the column is a statically determinate structure now. The displacement of the statically determinate structure subject to the uniform load is as follows:

$$
\delta_{y q_{y}}=\Delta_{i p} .
$$

The displacement of the statically determinate structure subject to the $F_{x i}$ is as follows:

$$
\delta_{x i F_{x i}}= \begin{cases}\frac{F_{x i} y^{2}}{6 E_{x} I_{x}}\left(3 a_{x i}-x\right), & 0 \leq x \leq a_{x i}, \\ \frac{F_{x i} a_{x i}^{2}}{6 E_{x} I_{x}}\left(3 x-a_{x i}\right), & a_{x i} \leq x \leq l_{x},\end{cases}
$$

where $q_{x}=0.7 \mathrm{~s}_{y} \mathrm{e}_{\mathrm{hk}}, l_{x}$ is the length of column, and $a_{x i}$ is the distance between the fixed end and $F_{x i}$.

Finally, the displacement of the column under earth pressure is as follows:

$$
\Delta_{x p}=\delta_{x q_{x}}-\sum_{i=1}^{n} \delta_{x i F_{x i}}
$$

At the same time, the beam becomes a statically determinate structure. The displacement of the statically determinate structure subject to the uniform load is as follows:

$$
\delta_{y q_{y}}=\frac{q_{y} y}{24 E_{y} I_{y}}\left(l_{y}^{3}+y^{3}+2 l_{y} y^{2}\right) .
$$

The displacement of the statically determinate structure subject to the $F_{y j}$ is as follows:

$$
\delta_{y j F_{y j}}= \begin{cases}\frac{F_{y j}\left(l_{y}-a_{y j}\right)}{6 l_{y} E_{y} I_{y}}\left(l_{y}^{2}-r_{y}^{2}-y^{2}\right), & 0 \leq y \leq a_{y j}, \\ \frac{F_{y j} a_{y j}\left(l_{y}-y\right)}{6 l_{y} E_{y} I_{y}}\left(2 l_{y} y-y^{2}-a_{y j}^{2}\right), & a_{y j} \leq y \leq l_{y},\end{cases}
$$

where $q_{y}=0.7 \mathrm{~s}_{x} \mathrm{e}_{\mathrm{hk}}, l_{y}$ is the length of beam, and $a_{y j}$ is the distance between the fixed end and $F_{y j} . R=l_{y}-a_{y j}$.

The displacement of the beam under earth pressure is as follows:

$$
\Delta_{y p}=\delta_{y q_{y}}-\sum_{j=1}^{m} \delta_{y j F_{y j}}
$$

3.3. Bending Moment Calculation under Lateral Earth Pressure. When the force $F_{x i}$ acts alone on the column, the bending moment $\bar{M}_{F_{x i}}$ is as follows: 


$$
\bar{M}_{F_{x i}}= \begin{cases}0, & 0 \leq x \leq(i-1) s_{x}, \\ F_{x i}\left(l_{x}-s_{0}-x\right), & (i-1) s_{x} \leq x \leq l_{x}-s_{0} .\end{cases}
$$

The bending moment of the column underlateral earth pressure is as follows:

$$
M_{x p}=M_{x q_{x}}-\bar{M}_{F_{x i}} .
$$

The bending moment of the beam underlateral earth pressure can be described as follows:

$$
M_{y p}=\alpha_{M} q_{y} s_{y}^{2}
$$

where $\alpha_{M}$ is the coefficient of bending moment.

\section{Deformation and Bending Moment Calculation under the Prestress of Anchors}

With the deformation of the column and beam, there is a certain compression deformation on the soil behind the supporting structure. The columns and beams are tied together by steel bars, so the columns and beams of the frame structure are working as a whole system to bear the load. The previous studies not only neglected the deformation of the soil but also calculated the beam and column separately, which will affect the analysis results of the structure. In this paper, the columns and beams are regarded as the bidirectional elastic foundation beam. As shown in Figure 3, the columns and beams are taken as the foundation beam, the soil behind the structure is treated as the foundation, and the anchors are treated as forces. Since the errors caused by the torque are small, the influence of the torque is ignored in the calculation [38].

4.1. Displacement Calculation under the Prestress of Anchors. As illustrated in Figure 4, during the designing of the frame structure with anchors, the bottom of the column is generally regarded as a fixed end. Therefore, the column is treated as a semi-infinite long beam, and the beam is taken as the free infinite beam [39].

Subjected to the concentrated force $P_{x i j}$ at the intersection of the column and the beam, the displacement at some point of the column and the beam can be expressed as follows:

$$
\begin{aligned}
& \left\{\begin{array}{l}
z_{i j}(x)=\frac{P_{x i j} \lambda_{x}}{2 k_{0} b_{x}}\left(A_{\lambda X_{x}}+2 D_{\lambda a_{x}} D_{\lambda x}+C_{\lambda a_{x}} C_{\lambda x}\right), \\
z_{i j}(y)=\frac{P_{y i j} \lambda_{y}}{2 k_{0} b_{y}} A_{\lambda X_{y}},
\end{array}\right. \\
& \left\{\begin{array}{l}
X_{x}=\left|x-a_{x}\right|, \\
X_{y}=\left|y-a_{y}\right|,
\end{array}\right.
\end{aligned}
$$

where $P_{i j}$ is the prestress of anchor at the intersection of the column and the beam, $P_{x i j}$ and $P_{y i j}$ are the distributed force on the column and beam, $\lambda_{x}$ and $\lambda_{y}$ are the rigid flexible eigenvalue of the column and beam, $b_{x}$ and $b_{y}$ are the section width of the column and beam, $X_{x}$ is the

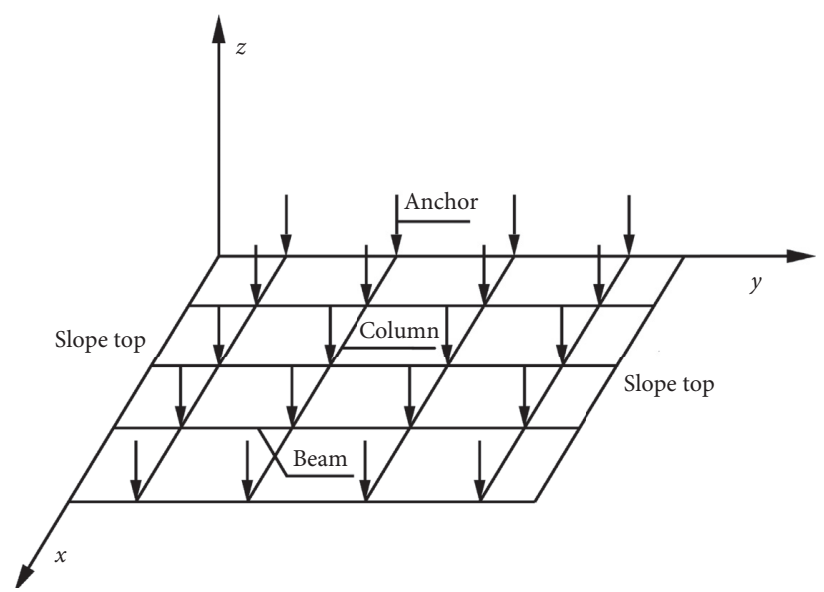

FIgURE 3: The plan of anchored-frame structures.

distance between $P_{x i j}$ and some point on the column, $a_{x}$ is the distance between $P_{x i j}$ and the end of the column, $X_{y}$ is the distance between $P_{y i j}$ and some point on the column and beam, and $a_{y}$ is the distance between $P_{y i j}$ and the end of the beam, and $k_{0}$ is the coefficient of subgrade reaction.

The value of the coefficient of subgrade reaction depends on many factors, such as elastic modulus, Poisson's ratio, and the beam's area. The coefficient of subgrade reaction of soil can be obtained as follows [40]:

$$
k_{0}=\frac{E_{0}}{0.88(1-\mu) \sqrt{A}},
$$

where $E_{0}$ is the elastic modulus of soil, $\mu$ is Poisson's ratio of soil, and $A$ is the area of beam.

For the anchored-frame structures, the column and beam are subjected to multiple concentrated forces at the same time, which should be superimposed to calculate the displacement of the entire column and beam.

$$
\left\{\begin{array}{l}
\delta_{x}=\sum_{i=1}^{n} P_{x i j} \frac{\lambda_{x}}{2 k_{0} b_{x}}\left(A_{\lambda X_{x}}+2 D_{\lambda a_{x}} D_{\lambda x}-C_{\lambda a_{x}} C_{\lambda x}\right), \\
\delta_{y}=\sum_{j=1}^{m} P_{y i j} \frac{\lambda_{y}}{2 k_{0} b_{y}} A_{\lambda X_{y}} .
\end{array}\right.
$$

Furthermore, to facilitate the expression, the coefficient of displacement is represented as follows:

$$
\left\{\begin{array}{l}
\eta_{x i j}=\frac{\lambda_{x}}{2 k_{0} b_{x}}\left(A_{\lambda X_{x}}+2 D_{\lambda a_{x}} D_{\lambda x}+C_{\lambda a_{x}} C_{\lambda x}\right), \\
\eta_{y j i}=\frac{\lambda_{y}}{2 k_{0} b_{y}} A_{\lambda X_{y}} .
\end{array}\right.
$$

The displacement of the column and beam are as follows:

$$
\left\{\begin{array}{l}
\delta_{x}=\sum_{i=1}^{n} P_{x i j} \eta_{x i j} \\
\delta_{y}=\sum_{j=1}^{m} P_{y i j} \eta_{y i j}
\end{array}\right.
$$




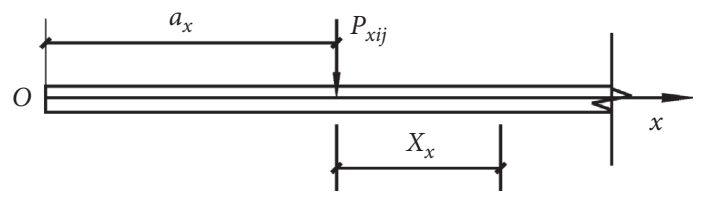

(a)

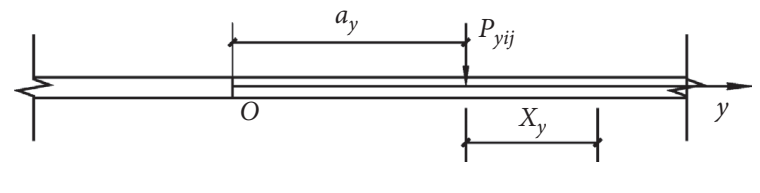

(b)

Figure 4: Elastic foundation beam model. (a) Column. (b) Beam.

where $\delta_{x}$ is the displacement of the column subject to $n$ concentrated forces, $\delta_{y}$ is the displacement of the beam subject to $n$ concentrated forces, $\eta_{x i j}$ is the displacement coefficient of the column under $m$ concentrated forces, and $\eta_{y i j}$ is the displacement coefficient of the beam under $m$ concentrated forces.

4.2. Bending Moment Calculation under the Prestress of Anchors. The calculation of bending moment is similar to that of deformation. The bending moment of the column and beam under the prestress of anchors are as follows:

$$
\left\{\begin{array}{l}
m_{x}=\sum_{i=1}^{n} \eta_{m_{x i}} P_{x j i} \\
m_{y}=\sum_{j=1}^{m} \eta_{m_{y j}} P_{y j i}
\end{array}\right.
$$

in which

$$
\left\{\begin{array}{l}
\eta_{m_{x i}}=\frac{1}{4 \lambda_{x}}\left(C_{\lambda X_{x}}-C_{\lambda a_{x}} A_{\lambda x}-2 D_{\lambda a_{x}} B_{\lambda x}\right), \\
\eta_{m_{y j}}=\frac{1}{4 \lambda_{y}} C_{\lambda X_{y}},
\end{array}\right.
$$

where $m_{x}$ is the bending moment of the column subject to $n$ concentrated forces, $\eta_{m_{x i}}$ is the bending moment coefficient of the column subject to $n$ concentrated forces, $m_{y}$ is the bending moment of the beam subject to $m$ concentrated forces, and $\eta_{m_{y j}}$ is the bending moment coefficient of the beam subject to $m$ concentrated forces.

4.3. Distribution of the Prestresses from the Anchors. Actually, the prestresses $P_{i j}$ of the anchor distribute $P_{x i j}$ to the column and $P_{y i j}$ to the beam. The key problem is how to distribute the force to the directions of the column and beam. The column and beam are orthogonal, and the deformation of column is equal to the deformation of beam at the anchored points. The coordination conditions are as follows:

$$
\left\{\begin{array}{l}
P_{i j}=P_{x i j}+P_{y i j} \\
\delta_{x i j}=\delta_{y i j}
\end{array}\right.
$$

where

$$
\left\{\begin{array}{l}
x=l_{x}-s_{0}-(i-1) s_{x}, \\
y=(j-1) s_{y} .
\end{array}\right.
$$

Because the prestress of anchor does not act on the column or beam alone, it is necessary to use the deformation and the coordination condition in formula (29) and calculate equations (26) and (29) with MATLAB software to get $P_{x i j}$ or $P_{y i j}$.

\section{Total Deformation and Bending Moment of the Frame Structures}

5.1. Total Deformation Calculation of the Frame Structures. Substituting equations (15) and (26) into equation (1) can yield the deformation calculation formula of the column.

$$
\Delta_{x}=\delta_{x q_{x}}-\sum_{i=1}^{n} \delta_{x i F_{x i}}-\sum_{i=1}^{n} \eta_{x j i} P_{x j i} .
$$

Substituting equations (18) and (26) into equation (1) can yield the deformation calculation formula of the beam.

$$
\Delta_{x}=\delta_{y q_{y}}-\sum_{j=1}^{m} \delta_{y j F_{y j}}-\sum_{j=1}^{m} \eta_{y i j} P_{y i j} .
$$

5.2. Total Bending Moment Calculation of the Frame Structures. Substituting equations (20) and (27) into equation (2), the bending moment of column is as follows:

$$
M_{x}=M_{x q_{x}}-\bar{M}_{F_{x i}}-\sum_{i=1}^{n} \eta_{m_{x i}} P_{x j i} .
$$

Substituting equations (21) and (27) into equation (2), the bending moment of beam is as follows:

$$
M_{y}=\alpha_{M} q_{y} s_{y}^{2}-\sum_{j=1}^{m} \eta_{m_{y j}} P_{y j i} .
$$




\section{A Case Study}

6.1. Project Overview. A real road slope in Lanzhou, China, is used here as a case study, which has a height of $12.1 \mathrm{~m}$ and a sloping angle of $76^{\circ}$. There are no existing buildings around the slope. According to the site investigation and geological survey, the soil of the slope is a fill whose properties are summarized in Table 1.

In accordance with the design and calculation, this section of the slope reinforcement scheme determines the frame structure with anchors. The beam and column crosssectional area is $300 \mathrm{~mm} \times 300 \mathrm{~mm}$, the concrete strength grade is C25, and the elastic modulus of the beam and column both is $2.8 \times 10^{6} \mathrm{kN} / \mathrm{m}^{3}$. The design parameters of anchors are shown in Table 2.

6.2. The Finite Element Model. This paper combines the numerical simulation and the engineering examples to verify and analyze the rationality of the deformation and bending moment calculation formula. As shown in Figures 5 and 6, it is the model established by using PLAXIS 3D software.

The FEM model uses the Mohr-Coulomb failure criterion for the considered soil, and the model of the anchor and beam is an elastic-plastic model. The soil physical parameters are shown in Table 1. The elastic modulus of soil is $1.1 \times 10^{4} \mathrm{kPa}$, and Poisson's ratio of soil is 0.33 [41]. The slope is at an angle of $76^{\circ}$, and the support type is frame structure with anchors. There is the pile foundation with a diameter of $800 \mathrm{~mm}$ at the slope toe, which is using the "Embedded Beam." The material of the columns and beams is "Beam." The anchors are located at the junction of the columns and beams. The material of the free section of the anchor is a "Point-To-Point Anchor," and the anchor section is "Embedded Beam." The prestress parameters are shown in Table 2. The contact stiffness between the anchors and the soil and the contact stiffness of the column and beam are set to "manual," and the input value $\mathrm{R}_{\text {inter }}$ of the reduction factor corresponding to the interface angle of friction and cohesion is $2 / 3$.

6.3. Comparison of Calculation Results and Simulation Results. In order to verify the rationality of the deformation results of the frame structure with anchor calculated by the elastic foundation beam method, the numerical simulation was carried out by PLAXIS 3D software, and the analysis was carried out by MATLAB software. The calculation results and simulation results are shown in Figure 7. The parameter $\mathrm{A}_{i j}$ refers to the number of the $j^{\text {th }}$ anchor on the $i^{\text {th }}$ row beam, while the parameter $B_{j i}$ refers to the number on the $i^{\text {th }}$ anchor of the $j^{\text {th }}$ row column.

The distributed force on the beam and column is shown in Figure 7. Figure 7(a) is the distributed force in the column and beam direction on the first row beam. It is found that there is some distribution rule for the distributed force on the column and beam. The distributed force on the beam is smaller than the counterpart on the column on the first row beam. The force on the beam decreases from the middle to both ends. On the other hand, the force on the column increases from the middle to both ends. However, in Figure 7(b), it is opposite in the fifth row beam. The distributed force of the beam is greater than the counterpart of the column on the fifth row beam. Moreover, the force increases from the middle to both ends in the beam direction. Figure 7(c) shows that the distributed force is close to each other not only between the beam and column but also in the same direction. Meanwhile, the distributed force is symmetrical in the beam direction. Figure $7(\mathrm{~d})$ shows the distributed force in the column direction. In the column direction, the distributed force on the column decreases with the slope depth increase, while the distributed force of the beam is increased with the slope depth increase. In addition, the distributed force is not symmetrical in the column direction, which is different from the distributed force in the beam direction. As a result, the elastic foundation beam model should be different from the counterpart of the column model.

Further comparison between the calculation results and the simulation results for the third row beam and the second row column deformation is shown in Figure 8. Figure $8(a)$ is the deformation of the second row column between the calculation results and simulation results. The trend of the curves is basically the same. With the increase in slope height, the deformation of the column becomes more and more great. The deformation of the slope is the largest near the second row anchor, while the deformation is the most small at the slope toe. The deformation of the slope is larger at anchor points. Figure 8(b) presents the deformation of the third row beam between the calculation results and the simulation results. The deformation at the points of anchors is larger than the others, and on the other hand, the deformation on the other points is smaller, which leads to the deformation fluctuation. As shown in Figures 8(a) and 8(b), the simulation results are greater than the analytical results because the lateral earth pressure determination is based on the limit state and the earth pressure may result in the reverse displacement, while the lateral earth pressure in the FEM simulation is under normal service conditions that may not involve failure or the limit state of the soil. In other words, the lateral earth pressure in the analytical method is greater and, hence, causes certain error in the result. The characteristics of the shape indicates that the prestressing anchors can effectively control the development of large slope deformation, and the analyses mentioned above show the validity and feasibility of the analytical method.

The comparison of bending moments on the third row beam and the second row column is shown in Figure 9. Obviously, the trend of the curves is basically the same. 
TABLE 1: Soil properties of the fill in the studied slope.

\begin{tabular}{ccccc}
\hline Soil & Thickness $(\mathrm{m})$ & Unit weight $\gamma\left(\mathrm{kN} / \mathrm{m}^{3}\right)$ & Cohesion $c(\mathrm{kPa})$ & Angle of internal friction $\varphi\left({ }^{\circ}\right)$ \\
\hline Fill & $>20$ & 16 & 15.0 & 23.0 \\
\hline
\end{tabular}

Table 2: Anchor parameters.

\begin{tabular}{lccccc}
\hline Anchor number & Anchor position $H / \mathrm{m}$ & Free section length $L_{\mathrm{f}} / \mathrm{m}$ & Anchorage section $L_{\mathrm{a}} / \mathrm{m}$ & Anchor diameter $D / \mathrm{mm}$ & Prestress $F_{0} / \mathrm{kN}$ \\
\hline 1 & 10.6 & 4 & 11 & 150 & 100 \\
2 & 8.1 & 4 & 13 & 150 & 150 \\
3 & 5.6 & 5 & 13 & 150 & 100 \\
4 & 3.1 & 6 & 10 & 150 & 100 \\
5 & 0.6 & 7 & 7 & 100 \\
\hline
\end{tabular}

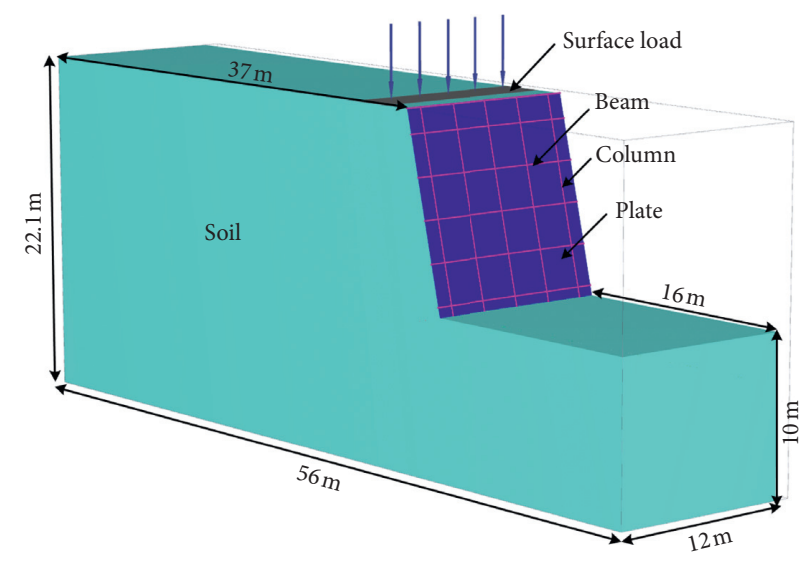

Figure 5: Slope support model.

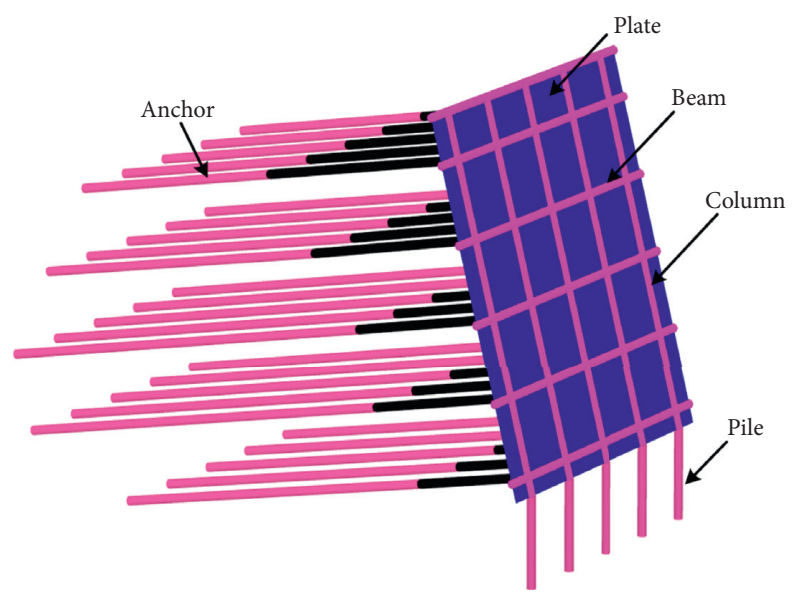

FIGURE 6: Structure model. 


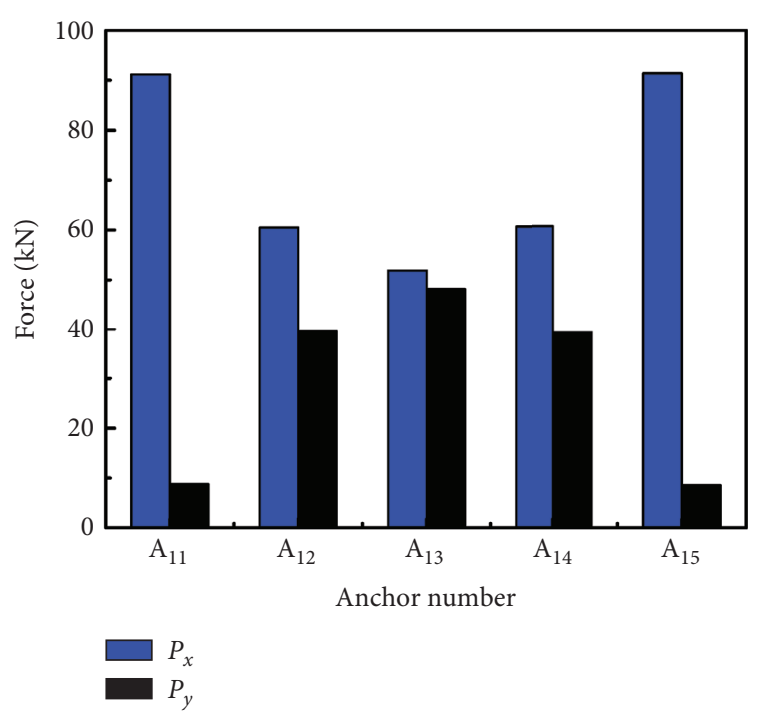

(a)

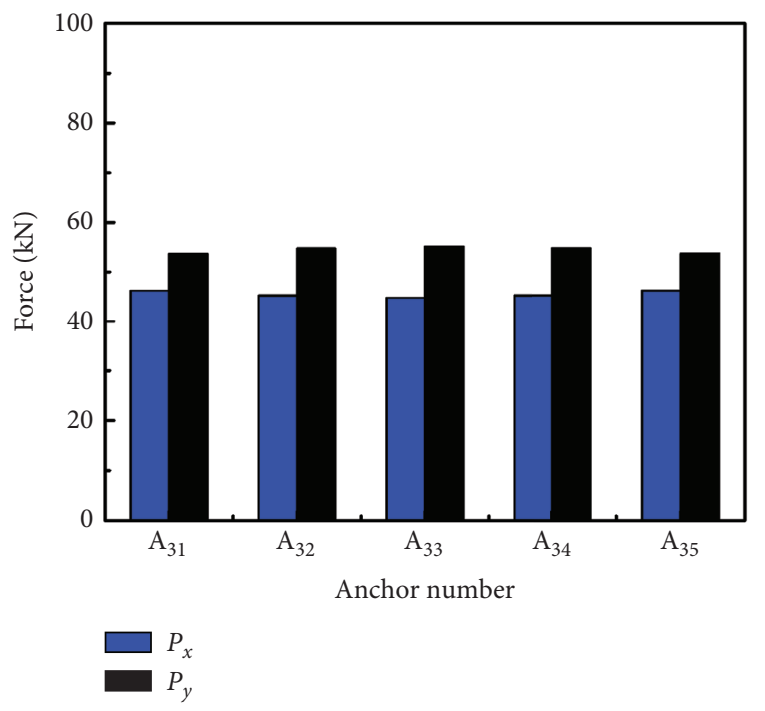

(c)

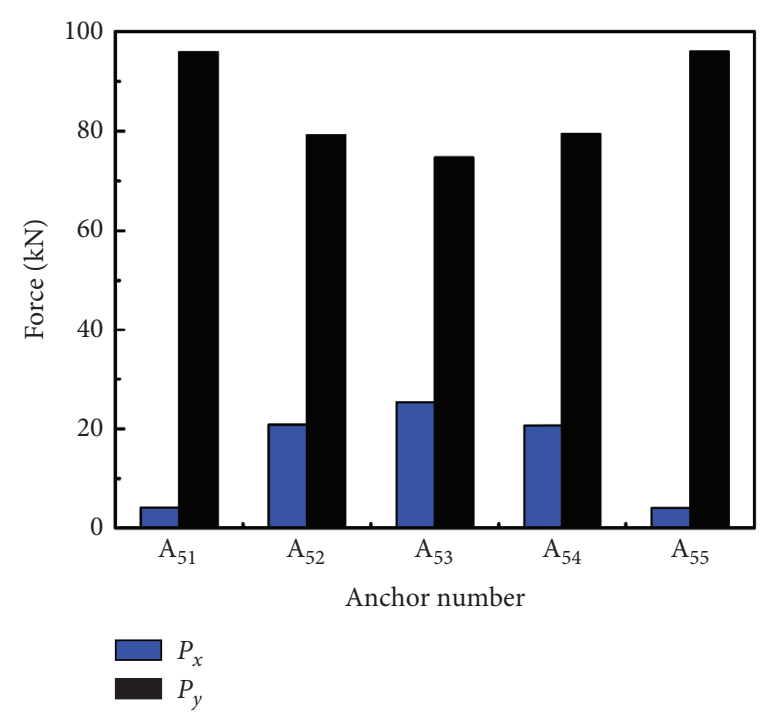

(b)

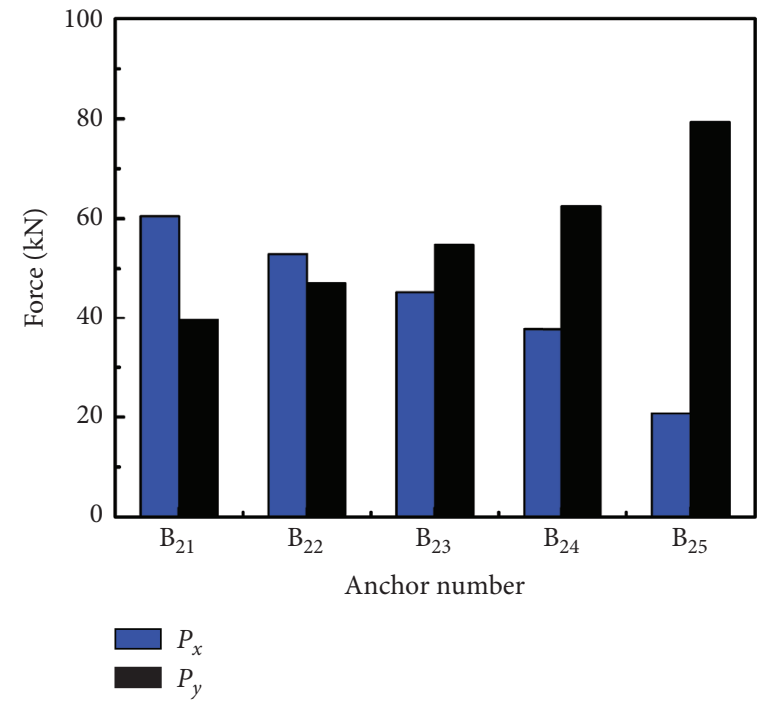

(d)

Figure 7: Distributed force. (a) The first row beam. (b) The fifth row beam. (c) The third row beam. (d) The second row column.

However, owing to the difference in the lateral earth pressure on the frame structure, the analytical result is generally slightly greater than that from the FEM simulation. The frame structure in the analytical result is subjected to the full lateral earth pressure on the slope, while the frame structure does not support the total lateral earth pressure in the FEM simulation. More interestingly, the bending moment on the beam is more uniformly distributed. The reason is that the forces on the third row beam are more uniformly distributed and the analytical model is symmetrical. In general, the result proves that the analytical method is viable and accurate. 


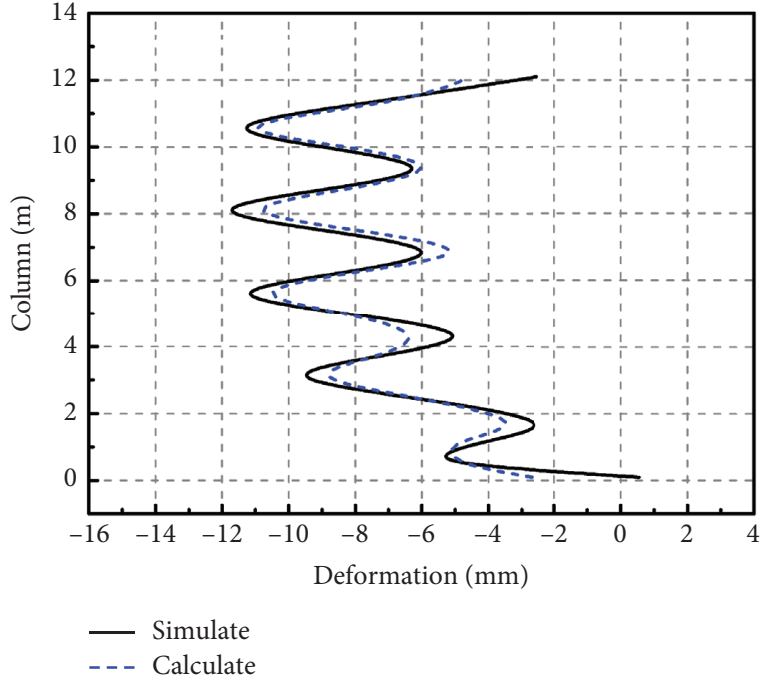

(a)

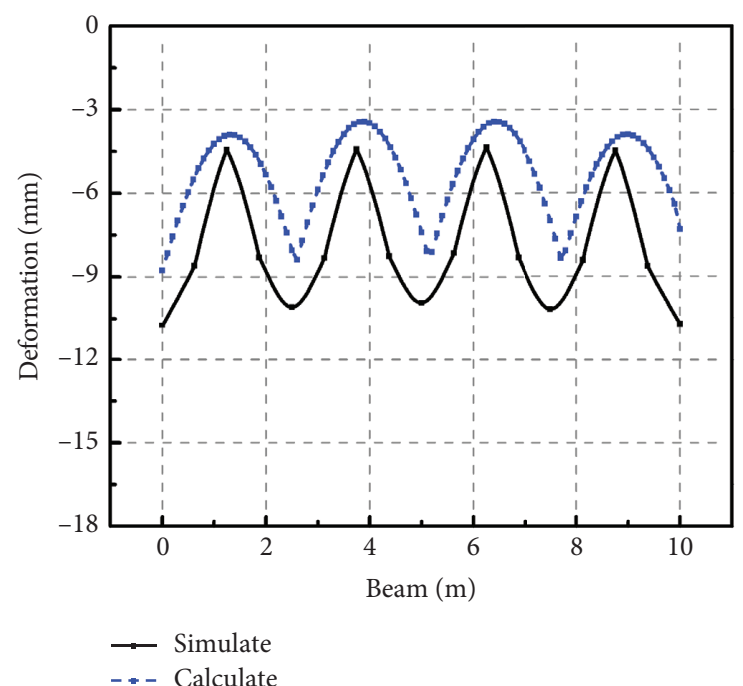

(b)

Figure 8: Deformation curve. (a) Column. (b) Beam.

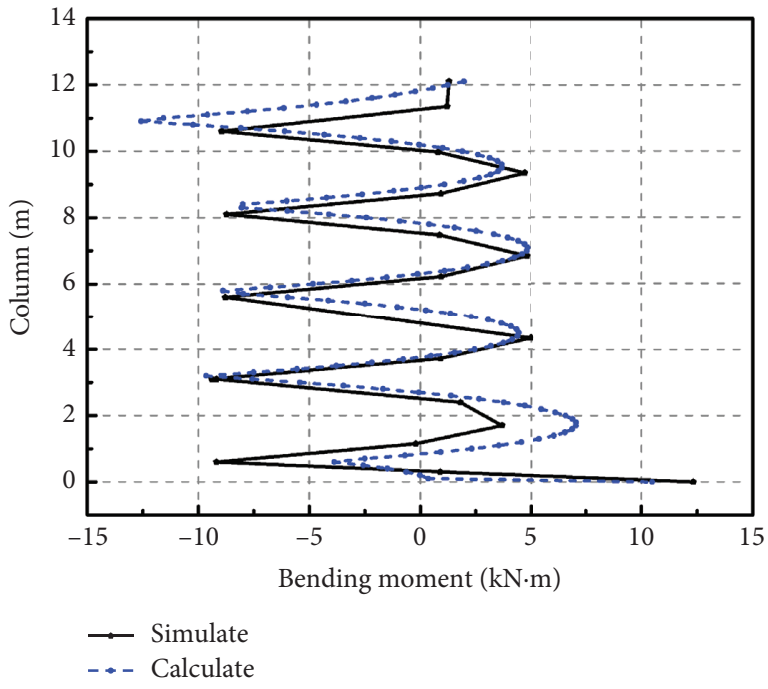

(a)

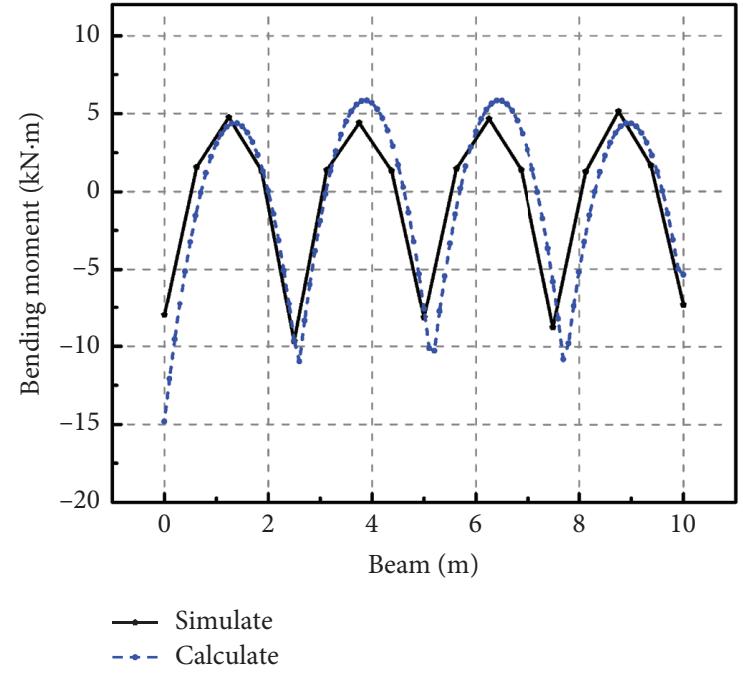

(b)

Figure 9: Bending moment curve. (a) Column. (b) Beam.

\section{Conclusions}

In this paper, the analytical method for the lateral earth pressure calculation under the anchored-frame structure is improved. The soil behind the frame structure with anchors is treated as a semi-infinite elastic body. The elastic foundation beam model is used to derive the deformation and bending moment calculation formula of the beam and column. At the same time, the finite element software PLAXIS 3D is used for the road slope engineering. The case and calculation results were compared and analyzed. The conclusions are as follows:

(1) The analytical method for the calculation of the distributed forces, deformation, and bending moments on the beam and column in the anchoredframe structure is implemented by Matlab, and results are compared with the FEM simulation by PLAXIS 3D. It is found that the calculation result is greater than the simulation result, but they are very close to each other, which indicates the correctness and feasibility of the analytical method.

(2) The distributed force, deformation, and bending moment are symmetrical along the direction of beam. The reason is that the infinitely long elastic foundation beam model used to the beam is symmetrical.

(3) Because the earth pressure is greater than simulation, the calculation result of deformation and bending 
moment is larger. Furthermore, the column displacement increases when the slope high increases.

(4) The analysis in this paper does not consider the effects of other events such as earthquakes and complex geological conditions, which will be further studied and discussed in subsequent investigations.

\section{Data Availability}

The data used to support the findings of this study are included within the article.

\section{Conflicts of Interest}

The authors declare that they have no conflicts of Interest.

\section{Acknowledgments}

The work described in this paper was fully supported by two grants from the National Natural Science Foundation of China (Award nos. 51568042 and 51768040).

\section{References}

[1] K. Shi, X. Wu, Z. Liu, and S. Dai, "Coupled calculation model for anchoring force loss in a slope reinforced by a frame beam and anchor cables," Engineering Geology, vol. 260, p. 105245, 2019 in English.

[2] G. Yang, Z. Zhong, Y. Zhang, and X. Fu, "Optimal design of anchor cables for slope reinforcement based on stress and displacement fields," Journal of Rock Mechanics and Geotechnical Engineering, vol. 7, no. 4, pp. 411-420, 2015, in English.

[3] C. S. Desai, A. Muqtadir, and F. Scheele, "Interaction analysis of anchor-soil systems," Journal of Geotechnical Engineering, vol. 112, no. 5, pp. 537-553, 1986, in English.

[4] R. D. Hryciw, "Anchor design for slope stabilization by surface loading," Journal of Geotechnical Engineering, vol. 117, no. 8, pp. 1260-1274, 1991, in English.

[5] Y. Tian, M. J. Cassidy, and W. Liu, "Optimising the dimensions of suction embedded anchors by investigating the opening mechanism," Ocean Engineering, vol. 183, pp. 350358, 2019, in English.

[6] M. F. Randolph, C. Gaudin, S. M. Gourvenec, D. J. White, N. Boylan, and M. J. Cassidy, "Recent advances in offshore geotechnics for deep water oil and gas developments," Ocean Engineering, vol. 38, no. 7, pp. 818-834, 2011, in English.

[7] C. Gaudin, M. J. Cassidy, C. D. O'Loughlin, Y. Tian, D. Wang, and S. Chow, "Recent advances in anchor design for floating structures," International Journal of Offshore and Polar Engineering, vol. 27, no. 1, pp. 44-53, 2017, in English.

[8] S. Ye, G. Fang, and Y. Zhu, "Model establishment and response analysis of slope reinforced by frame with prestressed anchors under seismic considering the prestress," Soil Dynamics and Earthquake Engineering, vol. 122, pp. 228-234, 2019, in English.

[9] S. H. Ye, G. W. Fang, and X. R. Ma, "Reliability analysis of grillage flexible slope supporting structure with anchors considering fuzzy transitional interval and fuzzy randomness of soil parameters," Arabian Journal for Science and Engineering, vol. 44, no. 6, pp. 8849-8857, 2019, in English.

[10] S. H. Ye and Z. F. Zhao, "Seismic response of pre-stressed anchors with frame structure," Mathematical Problems in
Engineering, vol. 202015 pages, 2020, in English, Article ID 9029045.

[11] S.-H. Ye and A.-P. Huang, "Sensitivity analysis of factors affecting stability of cut and fill multistage slope based on improved grey incidence model," Soil Mechanics and Foundation Engineering, vol. 57, no. 1, pp. 8-17, 2020, in English.

[12] S. H. Ye and Z. F. Zhao, "Allowable displacement of slope supported by frame structure with anchors under earthquake," International Journal of Geomechanics, vol. 20, no. 10, in English, Article ID 04020188, 2020.

[13] J. F. Zou, L. Li, and B. Ruan, "Analysis of displacement and deformation of anchor bolt under elastic state," China Railway Science, vol. 25, no. 5, pp. 94-96, 2004, in Chinese.

[14] Z. H. Tang and W. Y. Tang, "Discussion on calculation of soil anchor deformation," Geotechnical engineering, vol. 10, no. 9, pp. 27-28, 2007, in Chinese.

[15] M. H. Zhao, J. L. Liu, and Z. Long, "Deformation analysis of bolt and calculation of critical anchorage length," Journal Architecture Civil Engineering, vol. 25, no. 3, pp. 17-21, 2008.

[16] Y. Zhou, "Analysis and design of frame prestressed anchor support structure," M. Sc. Thesis, Lanzhou University of Technology, Lanzhou, China, 2004, in Chinese.

[17] Y. Zhou, Y. P. Zhu, and Y. Z. Ren, "Anchor deformation of flexible supporting system with prestressed anchors," China Railway Science, vol. 36, no. 3, pp. 58-65, 2015, in Chinese.

[18] Y. Liang, D. P. Zou, and G. Zhao, "Design of support of frame beam and prestressed anchor," Chinese Journal of Rock Mechanics and Engineering, vol. 25, no. 2, pp. 318-322, 2006, in Chinese.

[19] H. M. Tang, Y. Z. Xu, and X. S. Cheng, "Research on design theory of lattice frame anchor structure in landslide control engineering," Rock and Soil Mechanics, vol. 25, no. 11, pp. 1683-1687, 2004, in Chinese.

[20] S. G. Xiao and D. P. Zhou, "Internal force calculating method of prestressed-cable beam-on-foundation for high rock slope," Chinese Journal of Rock Mechanics and Engineering, vol. 22, no. 2, pp. 250-253, 2003, in Chinese.

[21] A. M. Han, J. G. Li, J. H. Xiao, and H. Z. Xu, "Mechanical behaviors of frame beam supporting structure with prestressed anchors," Rock and Soil Mechanics, vol. 31, no. 9, pp. 2894-2900, 2010, in Chinese.

[22] W. Fang and X. H. Liu, "Numerical simulation of reinforcement effect of high red clay cutting slope," Journal of Highway and Transportation Research and Development, vol. 29, no. 3, pp. 22-28, 2012, in Chinese.

[23] H. Zhang, Y. Lu, and Q. Cheng, "Numerical simulation of reinforcement for rock slope with rockbolt (anchor cable) frame beam," Journal of Highway and Transportation Research and Development (English Edition), vol. 25, no. 1, pp. 21-26, 2008, in Chinese.

[24] R. Bringkgreve and P. Vermeer, PLAXIS-finite Element Code for Soil and Rock Analysis, Plaxis BV, Delft, Netherlands, in English, 1998.

[25] A. P. S. Selvadurai and G. M. L. Gladwell, "Elastic analysis of soil-foundation interaction," Journal of Applied Mechanics, vol. 47, no. 1, in English, 1979.

[26] G. M. L. Gladwell, Contact Problems in the Classical Theory of Elasticity, Springer, Berlin, Germany, in English, 1980.

[27] S. M. He, X. L. Yang, and Y. J. Zhou, "Analysis of interaction of prestressed anchor rope foundation beam and foundation," Rock and Soil Mechanics, vol. 27, no. 1, pp. 83-88, 2006, in Chinese. 
[28] M. A. Biot, "Bengding of an infinite beam on an elastic foundation," Journal of Applied Mechanics, vol. 59, ASME, in English, pp. A1-A7, 1937.

[29] A. M. Zenkour, "A state of stress and displacement of elastic plates using simple and mixed shear deformation theories," Journal of Engineering Mathematics, vol. 44, no. 1, pp. 1-20, 2002, in English.

[30] K. M. Liew, J.-B. Han, Z. M. Xiao, and H. Du, "Differential quadrature method for Mindlin plates on Winkler foundations," International Journal of Mechanical Sciences, vol. 38, no. 4, pp. 405-421, 1996, in English.

[31] K. Terzaghi and R. B. Peck, Soil Mechanics in Engineering Practice, John Wiley \& Sons, New York, NY, USA, in English, 2nd edition, 1967.

[32] A. W. Bishop, "The use of the slip circle in the stability analysis of slopes," Géotechnique, vol. 5, no. 1, pp. 7-17, 1955, in English.

[33] Z. Y. Chen, M. Chi, P. Sun, and Y. J. Wang, "Simplified method of calculating active earth pressure for flexible retaining walls," Chinese Journal of Geotechnical Engineering, vol. 32, no. 1, pp. 22-27, 2010, in Chinese.

[34] X. S. Cao, S. G. Xiao, H. He, and S. X. Liu, "Model test on characteristics of slope pressure on multi-frame beams with anchor bolts used to stabilize high slope," Chinese Journal of Underground Space and Engineering, vol. 11, no. 5, pp. 1159-1163, 2015, in Chinese.

[35] S. Y. Zhao, Y. R. Zheng, P. He, and W. Zhang, "Discussion on calculation methods of slope lateral load," Chinese Journal of Underground Space and Engineering, vol. 13, no. 2, pp. 434441, 2017, in Chinese.

[36] L. X. Li and X. Z. Wang, "“Research on earth pressure considering deformation pattern of foundation pit supporting structure," Chinese Journal of Underground Space and Engineering, vol. 14, no. 4, pp. 1024-1033, 2018, in Chinese.

[37] People's Republic of China Industry Standards Compilation Group, Technical Code for Building Slope Engineering, GB 50330-2013, China Building Industry Press, Beijing, China, 2014, in Chinese.

[38] Y. Zhou and Y. P. Zhu, "Calculation of internal forces of framed flexible supporting structure with prestressed anchors based on torsional effects among beams and columns," Journal of Lanzhou University of Technology, vol. 35, no. 2, pp. 116-121, 2009, in Chinese.

[39] G. Zheng and X. L. Gu, Advanced Basic Engineering, Mechanical Industry Press, Beijing, China, 2007, in Chinese.

[40] X. F. Chen, Settlement Calculation Theory and Engineering Examples, Science Press, Beijing, China, 2005, in Chinese.

[41] L. J. He, Y. C. Shi, H. L. Yang, M. Q. Hu, and H. L. Xin, "Analysis stability of loess slope during different ground motion," Northwest Seismology Journal, vol. 31, no. 2, pp. 142-147, 2009, in Chinese. 